\title{
The relationship between patients' perception of type 2 diabetes and medication adherence: a cross-sectional study in Japan
}

Kana Hashimoto ${ }^{1 \dagger}$, Koki Urata ${ }^{1 \dagger}$, Ayano Yoshida ${ }^{1}$, Reiko Horiuchi ${ }^{2}$, Naoto Yamaaki ${ }^{3}$, Kunimasa Yagi ${ }^{4}$ and Kunizo Arai $^{1 *}$

\begin{abstract}
Background: The self-management of type 2 diabetes mellitus (T2DM), which involves adherence to medical instructions on diet and nutritional advice, physical activity, medication regimen, and weight and stress management, is necessary for the treatment of T2DM.

In this study, we investigated the relationship between patients' perceptions of their disease and their adherence to their medications. And we attempted to determine whether distinct subphenotypes of behavioral change of medication adherence can be discerned based on a patients' perceptions.

Method: A cross-sectional study using a questionnaire was conducted among 157 patients with T2DM from October 2015 to September 2017. Questionnaires were administered to assess the participants' demographic and clinical characteristics, medication adherence, diabetes knowledge, and perception of being diabetic. Principal component analysis (PCA) and cluster analyses were performed to classify medication adherence patterns in the total cohort. Multiple regression analyses were performed to identify the determinant factors of medication adherence.

Results: PCA showed the interpretable medication adherence of patients with diabetes by using component 1 ("accessibility to medical treatment") and component 2 ("status of taking medicines"). We identified four groups that show significantly different medication adherence by using cluster analysis on the basis of the two components. Multiple regression analysis showed that body mass index (BMI), family history of diabetes, one factor of patient's perception (living an orderly life), and diabetes knowledge were found to be significant predictors of medication adherence in patients with T2DM.

Conclusions: In patients with T2DM, the patient's diabetes perception of "living an orderly life" is associated with medication adherence. A poor adherence group may be able to change their adherence to diabetes treatment by developing the perception of "living an orderly life."
\end{abstract}

Keywords: Diabetes, Medication adherence, Illness perceptions, Community pharmacy, Hospital

\footnotetext{
* Correspondence: arai@p.kanazawa-u.ac.jp

${ }^{\dagger}$ Kana Hashimoto and Koki Urata contributed equally to this work.

${ }^{1}$ Faculty of Pharmacy, Institute of Medical, Pharmaceutical, and Health

Sciences, Kanazawa University, Kakuma-machi, Kanazawa 920-1192, Japan

Full list of author information is available at the end of the article
}

(c) The Author(s). 2019 Open Access This article is distributed under the terms of the Creative Commons Attribution 4.0 International License (http://creativecommons.org/licenses/by/4.0/), which permits unrestricted use, distribution, and reproduction in any medium, provided you give appropriate credit to the original author(s) and the source, provide a link to the Creative Commons license, and indicate if changes were made. The Creative Commons Public Domain Dedication waiver (http://creativecommons.org/publicdomain/zero/1.0/) applies to the data made available in this article, unless otherwise stated. 


\section{Background}

People with chronic conditions must be capable of self-management to protect their own health. Healthcare providers should provide support for patients facing health challenges who need assistance [1]. However, compliance with complex regimens and the self-care behavior of diabetic patients worsen over the long-term with lifestyle changes [2,3]. This is a serious problem for both patients and healthcare providers. Therefore, medical staff should understand the factors influencing patients' self-management behavior.

Self-management of type 2 diabetes mellitus (T2DM), which involves adherence to medical instructions on diet and nutrition, physical activity, medication regimen, and weight and stress management, is necessary for treating T2DM [4-6]. Adherence to diabetes therapy can improve patients' blood glucose control and help them avoid long-term complications [1, 7-9]. Furthermore, many studies have shown a strong association between diabetes perception and diabetes control [10-12].

Adherence to medical instructions and glycemic control are affected by several factors such as knowledge about diabetes [13], self-efficacy [14-17], depression [18-20], medical beliefs [21, 22], medical cost, and social support. Disease perception is thought to be an important psychosocial factor that can motivate patients to self-manage their diabetes. Their perception of the illness is formed by the cause, duration, awareness of symptoms, and controllability of the disease, along with a patient-created schematic diagram of the disease. Many studies have demonstrated that the illness perception of diabetic patients influences their self-care behavior [23-25], but little quantitative research concerning a relationship between medication adherence and illness perceptions of T2DM was found.

Illness perception questionnaires for various medical conditions have been developed recently to examine patients' perceptions about their diseases, symptoms, and causes [26]. Kamatani et al. [27] reported that T2DM patients form perceptions of diabetes in a similar manner to disease acceptance; they addressed this issue for T2DM in Japan by creating a new illness perception questionnaire (asking about the patient's diabetic profile) for understanding the patients' perception of their disease. They studied the relationship between blood glucose control and the T2DM patients' perception of their disease. Although some patient and treatment characteristics are predictive of lower adherence in therapy, characteristics of patients' perceptions associated with anti-diabetic treatments nonadherence remain unclear. The patient's perceptions of diabetes may offer new insights into glycemic control variations in T2DM patients. Further, healthcare providers can focus on behavioral approaches to managing T2DM by understanding the patients' illness perception.
The primary aim of this study was to investigate the relationship between patients' perceptions of T2DM and medication adherence. Secondary aims were (1) to categorize a behavioral subphenotypes of medication adherence in T2DM using a custom medication adherence assessment tool, developed by Ueno et al. (2) to report the behavioral profile associated with the behavioral subphenotypes of medication adherence, and (3) to investigate the relationship between behavioral subphenotypes of medication adherence in T2DM.

\section{Methods}

A cross-sectional study using a questionnaire was conducted from October 2015 to September 2017. This study included adults who were (1) aged over 20 years, (2) diagnosed with T2DM for at least one year, and (3) outpatients of a community pharmacy or a hospital in the Ishikawa Prefecture. The patients were recruited at a community pharmacy (Aozora Pharmacy) or at the Japan Community Healthcare Organization (JCHO) Kanazawa Hospital and Kanazawa University Hospital. After obtaining informed written consent, data was collected using an interview questionnaire that had four domains, namely: (1) demographic and clinical characteristics, (2) medication adherence, (3) illness perceptions about diabetes, and (4) diabetes knowledge.

The experimental methods were approved by the Kanazawa University of Medicine Ethics Committee and the JCHO Kanazawa Hospital Ethics Committee. All work was conducted in accordance with the Declaration of Helsinki and ethical principles for clinical research. Written informed consent was obtained from all patients.

\section{Demographic and clinical characteristics}

We collected data on patients' age, sex, body mass index (BMI), diabetes duration, family history of diabetes, microvascular complications, important comorbidities, and treatment modalities (different types of insulin therapy). Their glycemic control levels (HbA1c), number of medications, number of doses per day, history of microvascular complications, and important comorbidities were obtained from the chart data. The microvascular complication status was defined as the presence of retinopathy, neuropathy, or nephropathy.

\section{Medication adherence}

Ueno et al. [28] developed new medication adherence scale factors (subscale factor 1: collaboration with healthcare providers; subscale factor 2: motivation for collecting and utilizing medication-related information and utilization of information regarding medication; subscale factor 3: agreement with taking medication and its fit with their lifestyle; subscale factor 4: current state of medication use) and evaluated their reliability and validity. Medication 
adherence was assessed using the Ueno method. The medication adherence scale can be used with all items or each of the four subscale areas alone. The total score and the sum of each of the four subscale regions were calculated, and a higher score represents better medication implementation. The contents of each of the four subscale regions in the entire medication adherence were also evaluated. The medication adherence questionnaire about diabetes was shown in Additional file 1: Table S1.

\section{Illness perceptions about diabetes}

The illness perception questionnaire, developed by Kamatani et al. [27], was used to collect data on the participants' perceptions of their diabetes. The questionnaire consisted of 29 items and 7 factors (factor 1: feeling of inferiority; factor 2: living an orderly life; factor 3 : feeling of restriction; factor 4 : feeling miserable; factor 5 : feeling of getting into trouble; factor 6: feeling of overindulgence; factor 7: feeling of importance). The questionnaire for illness perceptions about diabetes was shown in Additional file 2: Table S2.

\section{Diabetes knowledge}

We used the revised Michigan Diabetes Knowledge Scale (DKT) [29] to measure the patients' knowledge of diabetes treatment. The revised DKT comprises a 20-item tool with two subscales. The first 18 questions comprise the general diabetes knowledge section for patients with either type 1 diabetes or T2DM. The insulin use subscale comprises two items and is only appropriate for use with patients being treated with insulin. Thus, we used only the general knowledge subscale because this study enrolled T2DM patients regardless of the treatment regimen. The revised Michigan Diabetes Knowledge Scale (DKT) was shown in Additional file 3: Table S3.

\section{Statistical procedures and analyses}

The significance of the demographic characteristic differences among the study patients was assessed using the Mann-Whitney U test or Fisher's exact test between two sets of observations, and the Kruskal-Wallis test was performed for three or more variables. The statistical significance of the individual differences was evaluated using Haberman's residual analysis and the Bonferroni method if the analysis of variance was significant. The relationships between the total medication adherence score and the patient characteristics were analyzed using Spearman's rho statistic $(\rho)$.

Principal component analysis (PCA) and cluster analyses were performed for the total cohort. Medical adherence patterns were extracted with PCA using the correlation matrix. To determine the number of retained components, the proportion of the variance explained by the components was used. In particular, two components were retained because they explained $85 \%$ of the medication adherence. For multiple group comparisons of patient perception and patient characteristics between medication adherence groups, we used analysis of variance. For correlations among age, BMI, family history of diabetes, two factors of illness perceptions about diabetes (factor 2: living an orderly life and factor 6: feeling of overindulgence), and diabetes knowledge, Spearman's correlation coefficient was used. Subsequently, we conducted multiple regression analyses with medication adherence as the dependent variable.

Data from the questionnaires were analyzed using the Statistical Package for Social Sciences (SPSS version 25; IBM Japan, Tokyo, Japan), with a $p$-value $<0.05$ considered statistically significant.

\section{Results}

\section{Demographic/clinical characteristics and illness perceptions about diabetes and diabetes-specific knowledge}

A total of 90 and 67 patients with T2DM participated in the hospital and community settings, respectively. The participants' demographics in each setting are shown in Table 1. The two groups were comparable regarding diabetes duration, diabetes knowledge, and patient's perceptions; however, the mean age and the proportion of the females in the community pharmacy patients were higher than those of the hospital patients. Moreover, more of the hospital patients received insulin treatments than the community pharmacy patients. The mean age for the total sample population was 65.8 years, and the sample population was comprised of $69.2 \%$ men. The patients' median BMI was 24.0. The sex distribution and age of this sample population were different from those of the whole population of the hospital and community pharmacy. The median duration of diabetes in the sample population was 11.0 years. A positive family history of diabetes mellitus was reported by $55.3 \%$ of the sample population. Approximately $30 \%$ of the sample population reported having complications, including diabetic retinopathy $(8.8 \%)$, diabetic nephropathy $(6.3 \%)$, diabetic neuropathy (10.1\%), and cardiac problems (11.3\%). Insulin therapy was administered to $34 \%$ of the patients. The number of doses taken by the patients was 8 per day, and 5 medications were prescribed. The average total score of knowledge about the disease (general features of diabetes, diet, physical activity, and complications) was 9.8 (out of a maximum of 18 on the general knowledge subscale).

\section{Clustering medication adherence behavior}

Table 2 shows the correlation between the total medication adherence score and patient characteristics. Significant relationships were found between medication adherence and BMI, family history of diabetes, diabetes knowledge, 
Table 1 Demographic and clinical characteristics of patients with type 2 diabetes at study entry

\begin{tabular}{|c|c|c|c|c|c|c|c|c|}
\hline & & \multicolumn{2}{|l|}{ Total } & \multicolumn{2}{|l|}{$\begin{array}{l}\text { Hospital } \\
(n=92)\end{array}$} & \multicolumn{2}{|c|}{$\begin{array}{l}\text { Community pharmacy } \\
(n=67)\end{array}$} & \multirow[t]{2}{*}{$p$-value } \\
\hline & & $n$ & $\%$ & $n$ & $\%$ & $n$ & $\%$ & \\
\hline \multirow[t]{2}{*}{ Gender } & male & 110 & 69.2 & 72 & 78.3 & 38 & 56.7 & $0.005^{*}$ \\
\hline & female & 49 & 30.8 & 20 & 21.7 & 29 & 43.3 & \\
\hline Age (year) & $\begin{array}{l}\text { median } \\
\text { [range] }\end{array}$ & $\begin{array}{l}68 \\
{[32-88]}\end{array}$ & & $65[32-87]$ & & $70[42-88]$ & & $0.001^{*}$ \\
\hline BMl & $\begin{array}{l}\text { median } \\
\text { [range] }\end{array}$ & $\begin{array}{l}24.0 \\
{[15.2-34.8]}\end{array}$ & & 24.0[15.9-34.8] & & 24.0[15.2-34.0] & & 0.446 \\
\hline Diabetes Duration (year) & $\begin{array}{l}\text { median } \\
\text { [range] }\end{array}$ & $\begin{array}{l}11,0 \\
{[0-55]}\end{array}$ & & $12.0[0-55]$ & & $10.0[1-53]$ & & 0.447 \\
\hline $\begin{array}{l}\mathrm{HbA1c} \\
(\%)\end{array}$ & $\begin{array}{l}\text { median } \\
\text { [range] }\end{array}$ & $\begin{array}{l}7.0 \\
{[4.4-10.6]}\end{array}$ & & $\begin{array}{l}7.0 \\
{[4.4-10.0]}\end{array}$ & & $\begin{array}{l}7.1 \\
{[5.9-10.6]}\end{array}$ & & 0.364 \\
\hline \multirow[t]{2}{*}{ Diabetes history of relatives } & yes & 88 & 55.3 & 48 & 52.2 & 40 & & 0.420 \\
\hline & no & 71 & 44.7 & 44 & 47.8 & 27 & & \\
\hline \multirow[t]{5}{*}{ Complications } & retinopathy & 14 & 8.8 & 9 & 9.8 & 5 & 7.5 & 0.779 \\
\hline & nephropathy & 10 & 6.3 & 8 & 8.7 & 2 & 3.0 & 0.193 \\
\hline & neuropathy & 16 & 10.1 & 8 & 8.7 & 8 & 11.9 & 0.596 \\
\hline & cardiovascular & 18 & 11.3 & 11 & 12.0 & 7 & 10.4 & 0.806 \\
\hline & non & 106 & 66.7 & 62 & 67.4 & 45 & 67.2 & 0.923 \\
\hline \multirow[t]{3}{*}{ Therapy } & exercise therapy & 52 & 32.7 & 33 & 35.9 & 19 & 28.4 & 0.393 \\
\hline & diet therapy & 71 & 44.7 & 47 & 51.1 & 24 & 35.8. & 0.075 \\
\hline & insulin therapy & 54 & 34.0 & 40 & 43.5 & 14 & 20.9 & $0.004^{*}$ \\
\hline $\begin{array}{l}\text { Diabetes knowledge } \\
\text { (the general knowledge subscale) }\end{array}$ & $\begin{array}{l}\text { average (SD) } \\
\text { [range] }\end{array}$ & $\begin{array}{l}9.8 \\
(3.4) \\
{[0-16]}\end{array}$ & & $\begin{array}{l}10.4 \\
(2.4) \\
{[4-16]}\end{array}$ & & $\begin{array}{l}8.9 \\
(4.2) \\
{[0-16]}\end{array}$ & & 0.050 \\
\hline Number of medications & $\begin{array}{l}\text { median } \\
\text { [range] }\end{array}$ & $\begin{array}{l}5 \\
{[1-20]}\end{array}$ & & $\begin{array}{l}5 \\
{[1-20]}\end{array}$ & & $\begin{array}{l}5 \\
{[1-17]}\end{array}$ & & 0.577 \\
\hline Number of doses per day & $\begin{array}{l}\text { median } \\
\text { [range] }\end{array}$ & $\begin{array}{l}8 \\
{[0-50]}\end{array}$ & & $\begin{array}{l}9 \\
{[1-50]}\end{array}$ & & $\begin{array}{l}8 \\
{[0-28]}\end{array}$ & & 0.137 \\
\hline \multirow[t]{7}{*}{ Patient's perception } & Factor 1. Feeling of inferiority & $\begin{array}{l}3.1 \\
(2.3) \\
{[0-10]}\end{array}$ & & $\begin{array}{l}3.0 \\
(2.2) \\
{[0-8]}\end{array}$ & & $\begin{array}{l}3.2 \\
(2.5) \\
{[0-10]}\end{array}$ & & 0.745 \\
\hline & Factor 2. Living a tidy life & $\begin{array}{l}6.9 \\
(2.1) \\
{[0-10]}\end{array}$ & & $\begin{array}{l}7.1 \\
(2.1) \\
{[0-10]}\end{array}$ & & $\begin{array}{l}6.8 \\
(2.1) \\
{[1-10]}\end{array}$ & & 0.195 \\
\hline & Factor 3. Feeling of restriction & $\begin{array}{l}5.2 \\
(1.9) \\
{[0.2-9]}\end{array}$ & & $\begin{array}{l}4.9 \\
(1.9) \\
{[0.2-8.6]}\end{array}$ & & $\begin{array}{l}5.5 \\
(1.7) \\
{[1-9]}\end{array}$ & & 0.076 \\
\hline & Factor 4. Feeling miserable & $\begin{array}{l}5.3 \\
(2.1) \\
{[0-10]}\end{array}$ & & $\begin{array}{l}5.6 \\
(2.1) \\
{[0-10]}\end{array}$ & & $\begin{array}{l}4.9 \\
(2.1) \\
{[0-9.67]}\end{array}$ & & 0.028 \\
\hline & Factor 5. Feeling of getting into trouble & $\begin{array}{l}3.9 \\
(1.9) \\
{[0-9.67]}\end{array}$ & & $\begin{array}{l}3.8 \\
(1.7) \\
{[0-7.17]}\end{array}$ & & $\begin{array}{l}3.9 \\
(2.2) \\
{[0-9.67]}\end{array}$ & & 0.919 \\
\hline & Factor 6 . Feeling of intemperance & $\begin{array}{l}6.2 \\
(1.9) \\
{[0-10]}\end{array}$ & & $\begin{array}{l}6.4 \\
(1.7) \\
{[2.33-10]}\end{array}$ & & $\begin{array}{l}6.1 \\
(2.2) \\
{[0-9.33]}\end{array}$ & & 0.797 \\
\hline & Factor 7. Feeling of portentous & $\begin{array}{l}6.5 \\
(2.0) \\
{[0.67-10]}\end{array}$ & & $\begin{array}{l}6.8 \\
(1.6) \\
{[2.33-10]}\end{array}$ & & $\begin{array}{l}6.0 \\
(2.3) \\
{[0.67-10]}\end{array}$ & & 0.013 \\
\hline
\end{tabular}


Table 2 The correlation between the total medication adherence score and patient characteristics

\begin{tabular}{|c|c|c|}
\hline & \multicolumn{2}{|c|}{ Total medication adherence score } \\
\hline & $\begin{array}{l}\text { coefficient of Spearman's } \\
\text { correlation }\end{array}$ & $p$-value \\
\hline Sex & 0.018 & 0.821 \\
\hline Age (years) & 0.098 & 0.217 \\
\hline BMl & -0.171 & $0.031^{*}$ \\
\hline Diabetes duration (years) & 0.154 & 0.053 \\
\hline $\mathrm{HbA1c}(\%)$ & -0.041 & 0.658 \\
\hline Family history of diabetes & 0.244 & $0.002^{*}$ \\
\hline \multicolumn{3}{|l|}{ Complications } \\
\hline retinopathy & 0.119 & 0.134 \\
\hline nephropathy & 0.008 & 0.919 \\
\hline neuropathy & 0.066 & 0.41 \\
\hline cardiovascular & 0.136 & 0.088 \\
\hline non & -0.101 & 0.206 \\
\hline \multicolumn{3}{|l|}{ Therapy } \\
\hline exercise therapy & 0.068 & 0.397 \\
\hline diet therapy & 0.112 & 0.159 \\
\hline insulin therapy & -0.029 & 0.72 \\
\hline Diabetes knowledge & 0.169 & $0.033^{*}$ \\
\hline Number of medications & 0.114 & 0.185 \\
\hline Number of doses per day & 0.154 & 0.073 \\
\hline \multicolumn{3}{|l|}{ Patients' perception } \\
\hline Factor 1. Feeling of inferiority & -0.119 & 0.134 \\
\hline Factor 2. Living an orderly life & 0.253 & $0.001^{* *}$ \\
\hline Factor 3. Feeling of restriction & 0.059 & 0.461 \\
\hline Factor 4. Feeling miserable & 0.039 & 0.63 \\
\hline $\begin{array}{l}\text { Factor } 5 \text {. Feeling of getting } \\
\text { into trouble }\end{array}$ & 0.064 & 0.428 \\
\hline $\begin{array}{l}\text { Factor } 6 \text {. Feeling of } \\
\text { overindulgence }\end{array}$ & 0.205 & $0.009^{* *}$ \\
\hline Factor 7. Feeling of importance & 0.035 & 0.665 \\
\hline
\end{tabular}

*significant at 0.05 level, ${ }^{* *}$ significant at 0.01 level

and two factors of patient's perception (factor 2: living an orderly life and factor 6 : feeling of overindulgence).

We investigated the profile of medication adherence in T2DM patients according to the medication adherence behavior. Considering that medication adherence has four subscale factors, the score for each subscale factor showed a characteristic for each patient with the same degree of adherence. Therefore, patients were classified into clusters by using a subordinate scale factor of medication adherence. We used PCA to reduce the number of medication adherence variables to a smaller number of independent dimensions. The varimax rotation was used to simplify the PC extracted, and the medication adherence between diabetic patients after the projection of variables and that of diabetic patients represented by components 1 and 2 , respectively, were summarized. The corresponding eigenvalues give the information percentages explained by these factors, namely, 52.5 and $23.8 \%$ for diabetic patients after the projection of variables and diabetic patients represented by components 1 and 2, respectively) (Table 3). Table 3 also shows three factors of adherence: subscale factor 1: collaboration with healthcare providers; subscale factor 2: motivation for collecting and using medication-related information; subscale factor 3: agreement to take medication and its fit with their lifestyle, which contribute strongly to component 1 ; and, by contrast, subscale factor 4 (the current state of medicine use) provided a large contribution to component 2 . Therefore, in this result, components 1 and 2 were respectively named as "accessibility to medical treatment" and "status of taking medicines" for convenience.

The scores of these two principal components were used for the cluster analysis (CA) by dividing the patient cohort into four groups. Table 4 shows the CA comparison of the four groups of variables. The first group (group 1) was characterized by high accessibility to medical treatment, the second group (group 2) demonstrated medium accessibility to medical treatment, the third group (group 3) had a high level of adherence for taking medicines, and the fourth group (group 4) showed low medication adherence. Figure 1 shows the scatter plot of all the patients. The X-axis (component 1 ) is mainly determined by variable prevalence and accessibility to medical treatment, whereas the Y-axis (component 2) is mainly determined by the level of medicine adherence (the variable adherence). Table 5 shows the patient characteristics for each group. The age, BMI, family history of diabetes, and the two factors of a patient's perception (factor 2: living an orderly life and factor 6: feeling of overindulgence) of this cohort were significantly different in the four groups. The characteristics of the groups

Table 3 Component loadings for medical adherence in varimax rotation principal components

\begin{tabular}{lll}
\hline & Component 1 & Component 2 \\
\hline $\begin{array}{l}\text { Subscale factor 1: collaboration } \\
\text { with healthcare providers }\end{array}$ & 0.77 & -0.434 \\
$\begin{array}{l}\text { Subscale factor 2: motivation of } \\
\text { collecting and utilizing medication- } \\
\text { related information and utilization } \\
\text { of information regarding medication }\end{array}$ & 0.834 & -0.34 \\
$\begin{array}{l}\text { Subscale factor 3: agreement with } \\
\text { taking medication and its fit with } \\
\text { their lifestyle }\end{array}$ & 0.73 & \\
$\begin{array}{l}\text { Subscale factor 4: the current state } \\
\text { of medication use }\end{array}$ & 0.526 & 0.311 \\
$\%$ cumulative variance & & 0.742 \\
\hline $\begin{array}{l}\text { Positive signs indicate that higher values of the varable are influential in the } \\
\text { \% }\end{array}$ & & \\
\hline
\end{tabular}

Positive signs indicate that higher values of the variable are influential in the component, whereas negative signs indicate the influence of lower values 
Table 4 Defining characteristics of the clusters

\begin{tabular}{lllll}
\hline Medication adherence & $\begin{array}{l}\text { Group 1 } \\
(n=58)\end{array}$ & $\begin{array}{l}\text { Group 2 } \\
(n=17)\end{array}$ & $\begin{array}{l}\text { Group 3 } \\
(n=66)\end{array}$ & $\begin{array}{l}\text { Group 4 } \\
(n=18)\end{array}$ \\
\hline $\begin{array}{l}\text { Component1 } \\
\text { Accessibility to medical }\end{array}$ & 0.87086 & 0.26542 & -0.61106 & -1.47487 \\
treatment & & & & \\
$\begin{array}{l}\text { Component 2 } \\
\text { Status of taking medicines }\end{array}$ & -0.01329 & -1.22898 & 0.82345 & -1.44393 \\
\hline
\end{tabular}

with good adherence (group1 and 3) were older and lower BMI than that of the poor adherence group. Moreover, patients in the good adherence groups have strong tendencies to live an orderly life and overindulgence about diabetes.

Association between medication adherence and demographic/clinical characteristics, illness perceptions about diabetes, and diabetes-specific knowledge in patients

Multiple regression analysis was performed to analyze predictors of medication adherence. BMI, family history of diabetes, one factor of patient's perception (factor 2: living an orderly life), and diabetes knowledge were found to be significant predictors of medication adherence of patients with T2DM (Table 6).

The explanatory variables of interest were BMI, family history of diabetes, patient's perception, and diabetes knowledge. Table 7 presents results of the multinomial logistic regression analysis of factors associated with adherence to medications by using group 1 (high level of adherence to medications) as a reference. There was a significant correlation between patients' perception of disease/diabetes knowledge and medication adherence. A low level of adherence to medications (group 4) was associated with patient's perception (odds ratio $(\mathrm{OR})=$ 0.697; $95 \%$ confidence interval (CI): 0.523-0.930). A medium level of adherence to medications (group 3) was associated with high BMI (OR $=1.159$; 95\% CI: $1.034-$ $1.300)$ and poor diabetes knowledge $(\mathrm{OR}=0.844 ; 95 \%$ CI: 0.741-0.961).

\section{Discussion}

We found that our study T2DM cohort was to categorize to four distinct subphenotypes according to a behavioral subphenotypes of medication adherence in T2DM patients using a validated medication adherence

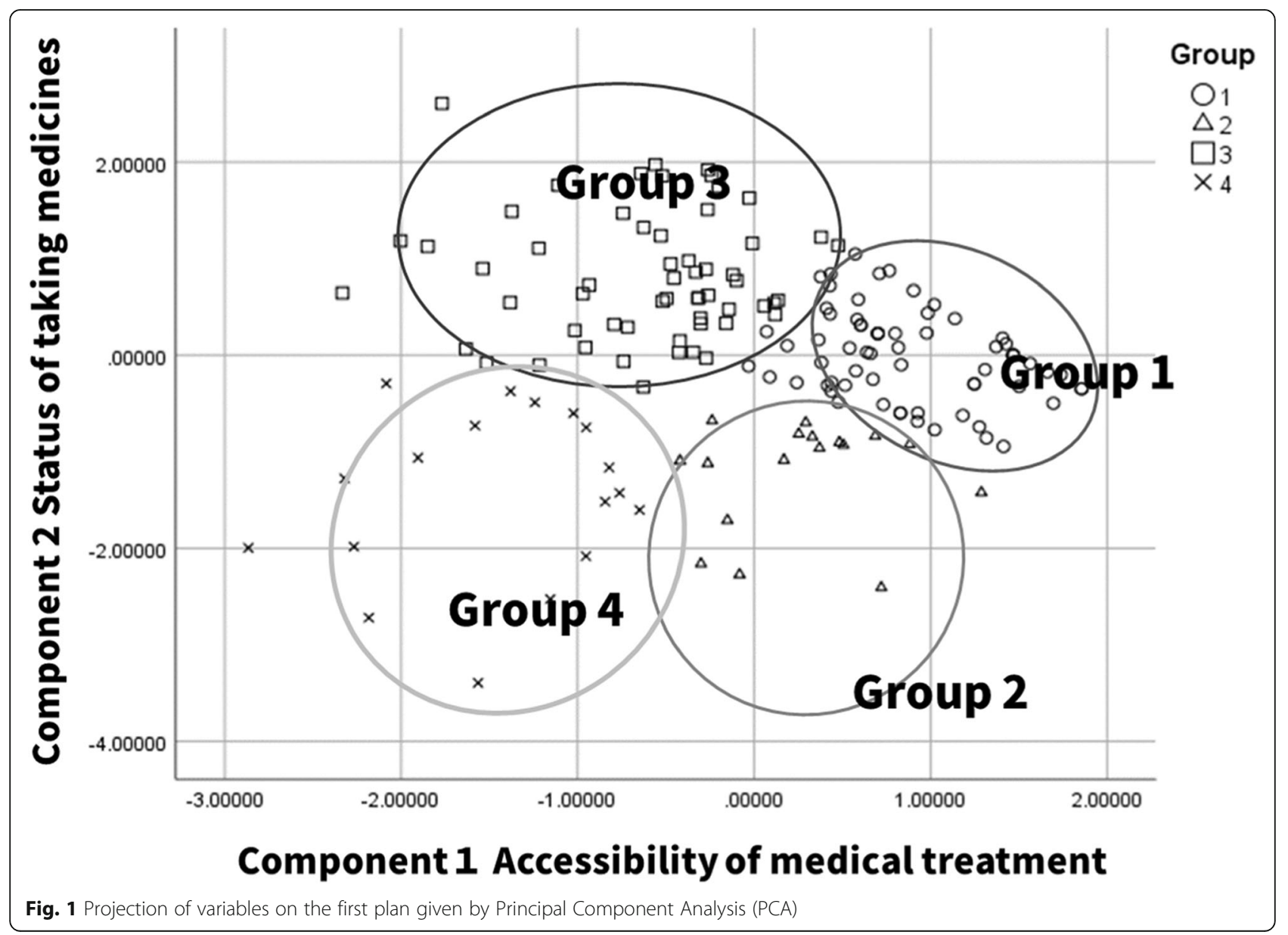


Table 5 Patient characteristics for each group

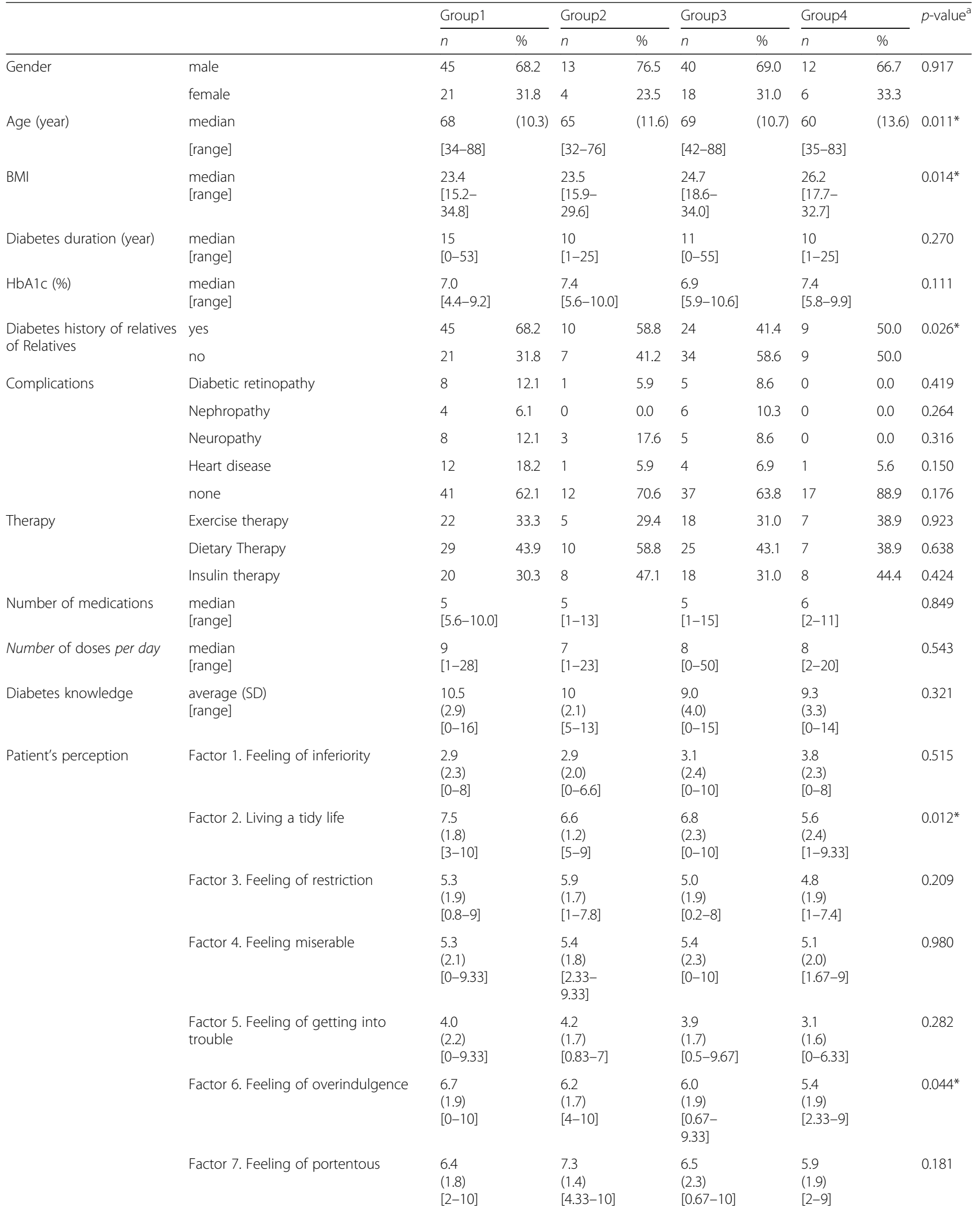


Table 6 Multivariable regression analysis for medication adherence

\begin{tabular}{llll}
\hline Variables & B & SE & $\beta$ \\
\hline Patients' perception factor 2: & 0.970 & 0.307 & $0.239^{* *}$ \\
Living an orderly life & & & \\
Family history of diabetes & 3.392 & 1.250 & $-0.198^{* *}$ \\
Diabetes knowledge & 0.504 & 0.192 & $0.199^{* *}$ \\
BMl & -0.391 & 0.170 & $-0.17^{*}$ \\
\hline
\end{tabular}

$B M I$ body mass index, $B$, partial regression coefficient for the constant in the null model. SE, the standard error around the coefficient for the constant. $\beta$, standard partial regression coefficient. *Significant at 0.05 level. **Significant at 0.01 level. The coefficient of determination (R2) in this regression equation was 0.195

scale and moreover the good adherence group was significantly associated with the patient's perception of "living an orderly life."

Diabetic patients adherence to their medication schedules more closely if they believe in medication efficacy and perceive their illness as manageable [29-34]. Patients with hypertension strongly believe that hypertension can be controlled by medical treatment $[35,36]$ or by managing their diets and lifestyle [37]; therefore, they strongly adhere to antihypertensive medications. Satisfaction, convenience, and effectiveness were associated with a good medication adherence in patients with dyslipidemia [38].

Measuring patient perception by Kamatani's method showed that diabetic patients who lived an orderly life had good medication adherence. Better adherence might be related to beliefs in medication efficacy and illness perceptions. Patients' perceptions change their viewpoint regarding life with T2DM, i.e., whether life goes forward depends on the disease or on their own initiative to live life responsibly. We hypothesized that positive recognition of diabetes and/or understanding of diabetes could be positively associated with the good medication adherence of T2DM patients. Therefore, we suggested devising strategies to promote illness perception that will help patients develop a customized diabetes health plan.

As another predictor of medical adherence in T2DM patients, BMI, diabetes knowledge, and family history of diabetes were identified. Tominaga et al. reported that older age was significantly associated with better medication adherence [39]. A high BMI (obesity) and a family history of diabetes are significantly and positively associated with the risk of T2DM progression [40-42]. A previous report showed that a family history of DM is associated with lower physical activity and noncompliance with dietary advice [43-45]. Diabetic patients' knowledge of their disease is one of the important determinants of self-management practices. This relationship is very important in diabetes intervention for medical providers and patients because knowledge of diabetes and self-management practice are significantly related to glycemic control $[46,47]$.

Table 7 Multinomial logistic regression results in medication adherence groups

\begin{tabular}{|c|c|c|c|c|}
\hline \multirow[t]{2}{*}{ Variables } & \multirow[t]{2}{*}{ B } & \multirow[t]{2}{*}{ Odds ratio } & \multicolumn{2}{|c|}{ 95\% confidence interval } \\
\hline & & & lower & upper \\
\hline \multicolumn{5}{|l|}{ Group 2} \\
\hline Age & $-0.055^{*}$ & 0.946 & 0.899 & 0.996 \\
\hline $\mathrm{BMI}$ & -0.078 & 0.925 & 0.787 & 1.088 \\
\hline Family history of diabetes & -0.350 & 1.419 & 0.447 & 4.506 \\
\hline Patients' perception factor 2: living an orderly life & -0.257 & 0.773 & 0.572 & 1.045 \\
\hline Diabetes knowledge & -0.049 & 0.952 & 0.789 & 1.150 \\
\hline \multicolumn{5}{|l|}{ Group 3} \\
\hline Age & 0.000 & 1.000 & 0.963 & 1.040 \\
\hline BMI & $0.148^{*}$ & 1.159 & 1.034 & 1.300 \\
\hline Family history of diabetes & $-1.250^{* *}$ & 3.490 & 1.580 & 7.709 \\
\hline Patients' perception factor 2: living an orderly life & -0.121 & 0.886 & 0.722 & 1.087 \\
\hline Diabetes knowledge & $-0.169^{*}$ & 0.844 & 0.741 & 0.961 \\
\hline \multicolumn{5}{|l|}{ Group 4} \\
\hline Age & $-0.072^{* *}$ & 0.931 & 0.882 & 0.982 \\
\hline BMI & 0.122 & 1.130 & 0.961 & 1.328 \\
\hline Family history of diabetes & -0.618 & 1.855 & 0.552 & 6.239 \\
\hline Patients' perception factor 2: living an orderly life & $-0.361^{*}$ & 0.697 & 0.523 & 0.930 \\
\hline Diabetes knowledge & -0.180 & 0.835 & 0.693 & 1.006 \\
\hline
\end{tabular}

BMI, body mass index; B. Partial regression coefficient; The coefficient of determination $\left(\mathrm{R}^{2}\right)$ in this regression equation was $0.273 .{ }^{*}$ significant at 0.05 level, ${ }^{* *}$ significant at 0.01 level 
There is a correlation between disease perception and health outcomes because self-management is complex. It involves complicated decision making that depends on the patients' perception of their illness in terms of whether it is controllable, understandable, curable, or serious [48-50]. We hypothesize that a poor adherence group can change their adherence to diabetes treatment by developing the perception of "living an orderly life."

This study has several limitations. The responses from the questionnaires were based on self-declaration; therefore, they are prone to potential errors and misunderstanding of the questions. In particular, the results of medication adherence may be subjected to recall bias and social desirability bias, especially when it comes to sensitive questions such as medication adherence. A cross-sectional design with convenience sampling was adopted in this study. There is a difference in the baseline characteristics of patients in the hospital vs. community settings, such as age and gender, considering that patients who have been visiting a pharmacy for a long time might readily agree to participate in this study. This could be a limitation as selection bias might have occurred for participants from the pharmacy.

\section{Conclusions}

We found that medication adherence in patients with T2DM is presumed by BMI, diabetes knowledge, family history of diabetes, and the diabetic patient's perception of "living an orderly life." Patients who have a perception of "living an orderly life" have good medication adherence. It may be beneficial to tailor health risk communications targeting T2DM to match the recipients' personality characteristics instead of using the "one-size-fits-all" approach. Future prospective studies are required to confirm the therapeutic effects of behavioral interventions for the perception of diabetes.

\section{Additional files}

\section{Additional file 1: Table S1. Medication adherence questionnaire.} (DOCX $16 \mathrm{~kb}$ )

Additional file 2: Table S2. Patients' perceptions of diabetes questionnaire. (DOCX $16 \mathrm{~kb}$ )

Additional file 3: Table S3. Revised Michigan Diabetes Knowledge Scale (DKT) - True/False Version. (DOCX 15 kb)

\section{Abbreviations}

BMl: Body mass index; DKT: Michigan Diabetes Knowledge Scale; PCA: Principal-component analysis; T2DM: Type 2 diabetes

\section{Acknowledgements}

Not applicable.

\section{Funding}

This work was supported by Grants-in-Aid for Scientific Research (KAKENHI, 17 K08439) from the Japan Society for the Promotion of Science.
Availability of data and materials

All data generated or analyzed during this study are included in this published article.

\section{Authors' contributions}

$\mathrm{KH}, \mathrm{KU}, \mathrm{AY}$ and $\mathrm{KA}$ conceived and designed this study. $\mathrm{KH}, \mathrm{KU}$ and $\mathrm{AY}$ collected and analyzed data. $\mathrm{RH}, \mathrm{NY}$ and $\mathrm{KY}$ supervised the conduct of this study. $\mathrm{KH}, \mathrm{KU}$, AY and KA drafted the manuscript, and all authors contributed substantially to its revision. All authors read and approved the final manuscript

\section{Ethics approval and consent to participate}

The study was approved by the each institution's ethics committees of Kanazawa University, and Japan Community Healthcare Organization (JCHO) Kanazawa Hospital.

\section{Consent for publication}

Not applicable.

\section{Competing interests}

The authors declare that they have no competing interests.

\section{Publisher's Note}

Springer Nature remains neutral with regard to jurisdictional claims in published maps and institutional affiliations.

\section{Author details}

${ }^{1}$ Faculty of Pharmacy, Institute of Medical, Pharmaceutical, and Health Sciences, Kanazawa University, Kakuma-machi, Kanazawa 920-1192, Japan.

${ }^{2}$ Gran Pharma Inc., 1-5-2 Hon-machi, Kanazawa 920-0853, Japan.

${ }^{3}$ Department of Internal Medicine, Japan Community Healthcare Organization Kanazawa Hospital, Ha-15 Oki-machi, Kanazawa 920-8610, Japan. ${ }^{4}$ Department of Internal Medicine, Graduate School of Medica Science, Kanazawa University, 13-1 Takara-machi, Kanazawa 920-8641, Japan.

Received: 23 August 2018 Accepted: 2 January 2019

Published online: 22 January 2019

\section{References}

1. Nie R, Han $Y, X u J$, Huang Q, Mao J. Illness perception, risk perception and health promotion self-care behaviors among Chinese patient with type 2 diabetes: a cross-sectional survey. Appl Nurs Res. 2018;39:89-96.

2. Hendrychova T, Vytrisalova M, Vlcek J, Smahelova A, Kubena AA. An analysis of fat-related and fiber-related behavior in men and women with type 2 diabetes mellitus: key findings for clinical practice. Patient Prefer Adherence. 2013;7:877-84.

3. Zhou Y, Liao L, Sun M, He G. Self-care practices of Chinese individuals with diabetes. Exp Ther Med. 2013;5:1137-42.

4. Cunningham AT, Crittendon DR, White N, Mills GD, Diaz V, LaNoue MD. The effect of diabetes self-management education on $\mathrm{HbA1c}$ and quality of life in African-Americans: a systematic review and meta-analysis. BMC Health Serv Res. 2018:18:367.

5. Schillinger D, Grumbach K, Piette J, Wang F, Osmond D, Daher C, Palacios J, Sullivan GD, Bindman AB. Association of health literacy with diabetes outcomes. JAMA. 2002;288:475-82.

6. Norris SL, Lau J, Smith SJ, Schmid CH, Engelgau MM. Self-management education for adults with type 2 diabetes a meta-analysis of the effect on glycemic control. Diabetes Care. 2002;25:1159-71.

7. Alatawi YM, Kavookjian J, Ekong G, Alrayees MM. The association between health beliefs and medication adherence among patients with type 2 diabetes. Res Social Adm Pharm. 2016;12:914-25.

8. Haas L, Maryniuk M, Beck J, Cox CE, Duker P, Edwards L, Fisher EB, Hanson L, Kent D, Kolb L, McLaughlin S, Orzeck E, Piette JD, Rhinehart AS, Rothman R, Sklaroff S, Tomky D, Youssef G. National standards for diabetes selfmanagement education and support. Diabetes Care. 2014;37(Suppl 1):S144-53.

9. Larkin AT, Hoffman C, Stevens A, Douglas A, Bloomgarden Z. Determinants of adherence to diabetes treatment. J Diabetes. 2015:7:864-71.

10. Abraham AM, Sudhir PM, Philip M, Bantwal G. Illness perceptions and perceived barriers to self-care in patients with type 2 diabetes mellitus: an exploratory study from India. Int J Diabetes Dev Countr. 2015;35:137-44. 
11. Broadbent E, Donkin L, Stroh JC. Illness and treatment perceptions are associated with adherence to medications, diet, and exercise in diabetic patients. Diabetes Care. 2011;34:338-40.

12. van Puffelen AL, Heijmans MJ, Rijken M, Rutten GE, Nijpels G, Schellevis FG. Illness perceptions and self-care behaviours in the first years of living with type 2 diabetes; does the presence of complications matter? Psychol Health. 2015;30:1274-87.

13. Al-Qazaz HK, Sulaiman SA, Hassali MA, Shafie AA, Sundram S, Al-Nuri R, Saleem F. Diabetes knowledge, medication adherence and glycemic control among patients with type 2 diabetes. Int J Clin Pharm. 2011;33:1028-35.

14. Huang YM, Shiyanbola OO, Chan HY. A path model linking health literacy, medication self-efficacy, medication adherence, and glycemic control. Patient Educ Couns 2018;18. pii: S0738-3991.

15. Chew BH, Vos RC, Pouwer F, Rutten GEHM. The associations between diabetes distress and self-efficacy, medication adherence, self-care activities and disease control depend on the way diabetes distress is measured: comparing the DDS-17, DDS-2 and the PAID-5. Diabetes Res Clin Pract. 2018;142:74-84.

16. Reisi M, Mostafavi F, Javadzade H, Mahaki B, Tavassoli E, Sharifirad G. Impact of health literacy, self-efficacy, and outcome expectations on adherence to selfcare behaviors in Iranians with type diabetes. Oman Med J. 2016;31:52-9.

17. Brown SA, García AA, Brown A, Becker BJ, Conn VS, Ramírez G, Winter MA, Sumlin LL, Garcia TJ, Cuevas HE. Biobehavioral determinants of glycemic control in type 2 diabetes: a systematic review and meta-analysis. Patient Educ Couns. 2016;99:1558-67.

18. Krass I, Schieback P, Dhippayom T. Adherence to diabetes medication: a systematic review. Diabet Med. 2015;32:725-37.

19. Jannoo Z, Wah YB, Lazim AM, Hassali MA. Examining diabetes distress, medication adherence, diabetes self-care activities, diabetes-specific quality of life and health-related quality of life among type 2 diabetes mellitus patients. J Clin Transl Endocrinol. 2017;9:48-54.

20. Lum ZK, Tsou KYK, Lee JY. Mediators of medication adherence and glycaemic control and their implications for direct outpatient medical costs: a cross-sectional study. Diabet Med. 2018;35:807-15.

21. Wei L, Champman S, Li X, Li X, Li S, Chen R, Bo N, Chater A, Horne R. Beliefs about medicines and non-adherence in patients with stroke, diabetes mellitus and rheumatoid arthritis: a cross-sectional study in China. BMJ Open. 2017;7:e017293.

22. Lam WY, Fresco P. Medication adherence measures: an overview. Biomed Res Int. 2015;217047:1-12.

23. Abubakari AR, Jones MC, Lauder W, Kirk A, Anderson J, Devendra D. Associations between knowledge, illness perceptions, self-management and metabolic control of type 2 diabetes among African and European-origin patients. J Nurs Healthc Chronic IIIn. 2011;3:245-56.

24. Bean D, Cundy T, Petrie KJ. Ethnic differences in illness perceptions, selfefficacy and diabetes self-care. Psychol Health. 2007;22:787-811.

25. Nsereko E, Bavuma C, Tuyizere M, Ufashingabire C, Rwakageyo JMV, Yamuragiye A. Illness perceptions and depression in relation to self-care behavior among type 2 diabetes patients in a referral hospital in KigaliRwanda. Rwanda J Health Sci. 2013;2:1-9.

26. Petrie KJ, Jago LA, Devcich DA. The role of illness perceptions in patients with medical conditions. Curr Opin Psychiatry. 2007;20:163-7.

27. Kamatani $Y$, Inagaki M, Tasaki K. Evaluation of the usefulness of a questionnaire created for the purpose of understanding type 2 diabetes patients' perception of the disease: the relation between patient perception and diabetes control. J Jpn Acad Nurs Sci. 2013;33:332-45.

28. Ueno $H$, Yamazaki $Y$, Ishikawa $H$. Reliability and validity of medication adherence scale for patients with chronic disease in Japan. JJHEP. 2014;22:13-29.

29. Kugbey N, Oppong Asante K, Adulai K. Illness perception, diabetes knowledge and self-care practices among type-2 diabetes patients: a crosssectional study. BMC Res Notes. 2017;10:381

30. Milicevic R, Jaksic N, Aukst-Margetic B, Jakovljevic M. Personality traits and treatment compliance in patients with type 2 diabetes mellitus. Psychiatr Danub. 2015:27(Suppl 2):586-9.

31. Lawson VL, Bundy C, Belcher J, Harvey JN. Changes in coping behavior and the relationship to personality, health threat communication and illness perceptions from the diagnosis of diabetes: a 2-year prospective longitudinal study. Health Psychol Res. 2013;1 (2):e20.

32. Lane JD, McCaskill CC, Williams PG, Parekh PI, Feinglos MN, Surwit RS Personality correlates of glycemic control in type 2 diabetes. Diabetes Care. 2000;23:1321-5
33. Shiyanbola OO, Nelson J. Illness perceptions, beliefs in medicine and medication non-adherence among South Dakota minority women with diabetes: a pilot study. S D Med. 2011;64:365-8.

34. MannDM PD, Leventhal $H$, Halm EA. Predictors of adherence to diabetes medications: the role of disease and medication beliefs. J Behav Med. 2009; 32:278-84.

35. Lo SH, Chau JP, Woo J, Thompson DR, Choi KC. Adherence to antihypertensive medication in older adults with hypertension. J Cardiovasc Nurs. 2016;31:296-303.

36. Morrison VL, Holmes EA, Parveen S, Plumpton CO, Clyne W, De Geest S, Dobbels F, Vrijens B, Kardas P, Hughes DA. Predictors of self-reported adherence to antihypertensive medicines: a multinational, cross-sectional survey. Value Health. 2015;18:206-16.

37. Rajpura J, Nayak R. Medication adherence in a sample of elderly suffering from hypertension: evaluating the influence of illness perceptions, treatment beliefs, and illness burden. J Manag Care Pharm. 2014;20:58-65.

38. Haddad C, Hallit S, Salhab M, Hajj A, Sarkis A, Ayoub EN, Jabbour H, Khabbaz LR. Association between adherence to statins, illness perception, treatment satisfaction, and quality of life among lebanese patients. J Cardiovasc Pharmacol Ther. 2018:23:414-22

39. Tominaga Y, Aomori T, Hayakawa T, Kijima N, Morisky DE, Takahashi K, Mochizuki M. Possible associations of personality traits representing harm avoidance and self-directedness with medication adherence in Japanese patients with type 2 diabetes. J Pharm Health Care Sci. 2018;4:16.

40. Sacco WP, Wells KJ, Friedman A, Matthew R, Perez S, Vaughan CA. Obesity and glycemic control in patients with diabetes mellitus: analysis of physician electronic health records in the US from 2009-2. J Diabetes Complicat. 2016;30:212-20.

41. Bao W, Yeung E, Tobias DK, Hu FB, Vaag AA, Chavarro JE, Mills JL, Grunnet LG, Bowers K, Ley SH, Kiely M, Olsen SF, Zhang C. Long-term risk of type 2 diabetes mellitus in relation to $\mathrm{BMI}$ and weight change among women with a history of gestational diabetes mellitus: a prospective cohort study. Diabetologia. 2015;58:1212-9.

42. Sacco WP, Wells KJ, Friedman A, Matthew R, Perez S, Vaughan CA. Adherence, body mass index, and depression in adults with type 2 diabetes: the mediational role of diabetes symptoms and self-efficacy. Health Psychol. 2007;26:693-700.

43. Scott RA, et al. The link between family history and risk of type 2 diabetes is not explained by anthropometric, lifestyle or genetic risk factors: the EPICInterAct study. InterAct Consortium, Diabetologia. 2013;56:60-9.

44. Wang C, Yatsuya H, Tamakoshi K, Toyoshima H, Wada K, Li Y, Hilawe EH, Uemura M, Chiang C, Zhang Y, Otsuka R, Ota A, Hirakawa Y, Aoyama A Association between parental history of diabetes and the incidence of type 2 diabetes mellitus differs according to the sex of the parent and offspring's body weight: a finding from a Japanese worksite-based cohort study. Prev Med. 2015:81:49-53.

45. Parajuli J, Saleh F, Thapa N, Ali L. Factors associated with nonadherence to diet and physical activity among Nepalese type 2 diabetes patients; a cross sectional study. BMC Res Notes. 2014;7:758.

46. Kassahun T, Gesesew H, Mwanri L, Eshetie T. Diabetes related knowledge, selfcare behaviours and adherence to medications among diabetic patients in Southwest Ethiopia: a cross-sectional survey. BMC Endocr Disord. 2016:16:28

47. Nagrebetsky A, Griffin S, Kinmonth AL, Sutton S, Craven A, Farmer A. Predictors of suboptimal glycaemic control in type 2 diabetes patients: the role of medication adherence and body mass index in the relationship between glycaemia and age. Diabetes Res Clin Pract. 2012;96:119-28.

48. Fitzgerald JT, Funnell MM, Hess GE, Barr PA, Anderson RM, Hiss RG, Davis WK. The reliability and validity of a brief diabetes knowledge test. Diabetes Care. 1998:21:706-10.

49. Lee SF, Teh XR, Malar LS, Ong SL, James RP. The associations of illness perception with metabolic control ( $\mathrm{HbA} 1 \mathrm{c})$ among type 2 diabetes mellitus patients in a district hospital. Int J Pharm Pract. 2017. https://doi.org/10. 1111/ijpp.12413.

50. Mc Sharry J, Moss-Morris R, Kendrick T. Illness perceptions and glycaemic control in diabetes: a systematic review with meta-analysis. Diabet Med. 2011:28:1300-10. 